\title{
Limiting the Influence of Regulated Electrical Drainage on Track Circuits
}

\author{
Roman Hrbac, Vaclav Kolar, Tomas Mlcak \\ Faculty of Electrical Engineering and Computer Science, VSB-Technical University of Ostrava, \\ 17. listopadu 15, Ostrava, Czech Republic \\ roman.hrbac@vsb.cz
}

\begin{abstract}
For the past two years, the authors of this paper have been working on the development of a new regulated electrical drainage system for tram tracks, which may also be used on railways in the future. When this drainage is used on train tracks equipped with track circuits, it is necessary to make sure that the drainage does not generate current harmonics which may be dangerous for the correct functioning of the circuits. In the Czech Republic, requirements regarding the operation of track circuits are stated by Standard CSN 342613. When the drainage was tested on tram tracks, where there are no track circuits, it was found out that in certain operation modes, the drainage generates frequencies which collide with the frequencies of track circuits. Therefore, a passive filter was designed to solve this problem. With the use of computer simulation and measurements on a laboratory model, it was verified that this filter is able to suppress unwanted current harmonics, so that they are in agreement with the above mentioned Standard. These measurements and simulations are described in this paper.
\end{abstract}

Index Terms-Electric traction; Electromagnetic compatibility; Harmonic filters; Railway safety.

\section{INTRODUCTION}

Pipelines which are located in the ground are threatened by corrosion. Great part of this corrosion is caused by DC stray currents leaking from electric traction tracks, such as tram and railway tracks (trolleybuses do not cause stray currents) [1]. Electric drainage helps protect pipelines from these stray currents, because it leads them safely back into the rails [2]. Currently, the most widely used regulated electrical drainage transmits current in only one direction and regulates its value by pulse width modulation. Current regulation starts when its value exceeds a set value, or when the potential of the protected pipeline drops below a certain value (usually $-2 \mathrm{~V}$ to $-3 \mathrm{~V}$; lower potential would lead to the release of hydrogen and increased brittleness of the steel pipeline). When the railway track is equipped with a track circuit, current harmonics generated by regulated electrical drainage can have a negative effect on its function, thus threatening railway safety [3], [4]. Standard ČSN 342613 [5] specifies the requirements on track circuits, as well as current harmonic values which are allowed in track circuit

Manuscript received 19 December, 2017; accepted 27 June, 2018. This research was funded by grant SP2018/163 "Diagnostics, reliability and efficiency of electrical machines and devices, problems of antenna systems" of VSB-TU Ostrava. protective frequency bands. In the Czech Republic, the most often used frequencies for track circuits are $50 \mathrm{~Hz}, 75 \mathrm{~Hz}$ and $275 \mathrm{~Hz}$. Harmonic values around these frequencies must be lower than limits stated by the Standard. This paper was written based on the development of regulated electrical drainage and it deals with ways to limit the influence of this drainage on track circuits. The problem was solved with the use of computer simulation, measurements on a tramway track without track circuits and on a laboratory model.

\section{DEVELOPMENT OF THE DRAINAGE}

When the development of the drainage was in process (see e.g. [6]), it was decided that the drainage should work with a switching frequency of $100 \mathrm{~Hz}$, with PWM duty cycle changing in 17 control stages from 0 (permanently switched on) to 16 (permanently switched off). 12 PWM periods form one control cycle, after which measured current values are evaluated and PWM duty cycle control stage may be changed if necessary. Control stages can be changed by 1 degree at most. The proportionally integrative control algorithm was selected due to its reliability. Although other solutions are based on adaptive regulation and self-learning are known [7].

Figure 1 shows the typical diagram of drainage connection between railway tracks and pipeline. Figure 2 shows the block diagram of the drainage developed by the authors.

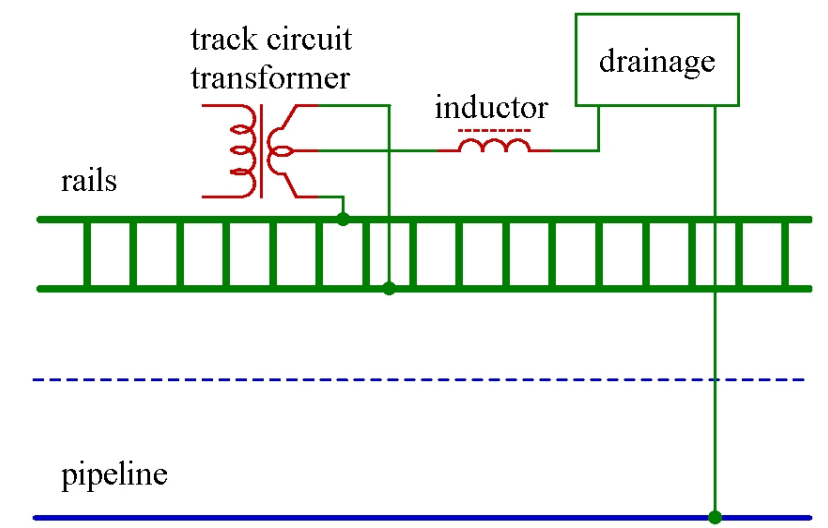

Fig. 1. Typical drainage connection on a railway track.

PWM switching frequency is $100 \mathrm{~Hz}$, and none of its multiples equals the frequencies used in track circuits $(50 \mathrm{~Hz}, 75 \mathrm{~Hz}, 275 \mathrm{~Hz})$. Under stable conditions drainage 
generates only switching frequency and its multiples [8]. This means that under normal conditions, the drainage does not generate frequencies which would interfere with track circuits. However, the situation is different in the case of transients, where changes in PWM duty cycle occur. In this situation, other frequencies than $100 \mathrm{~Hz}$ multiples are generated.

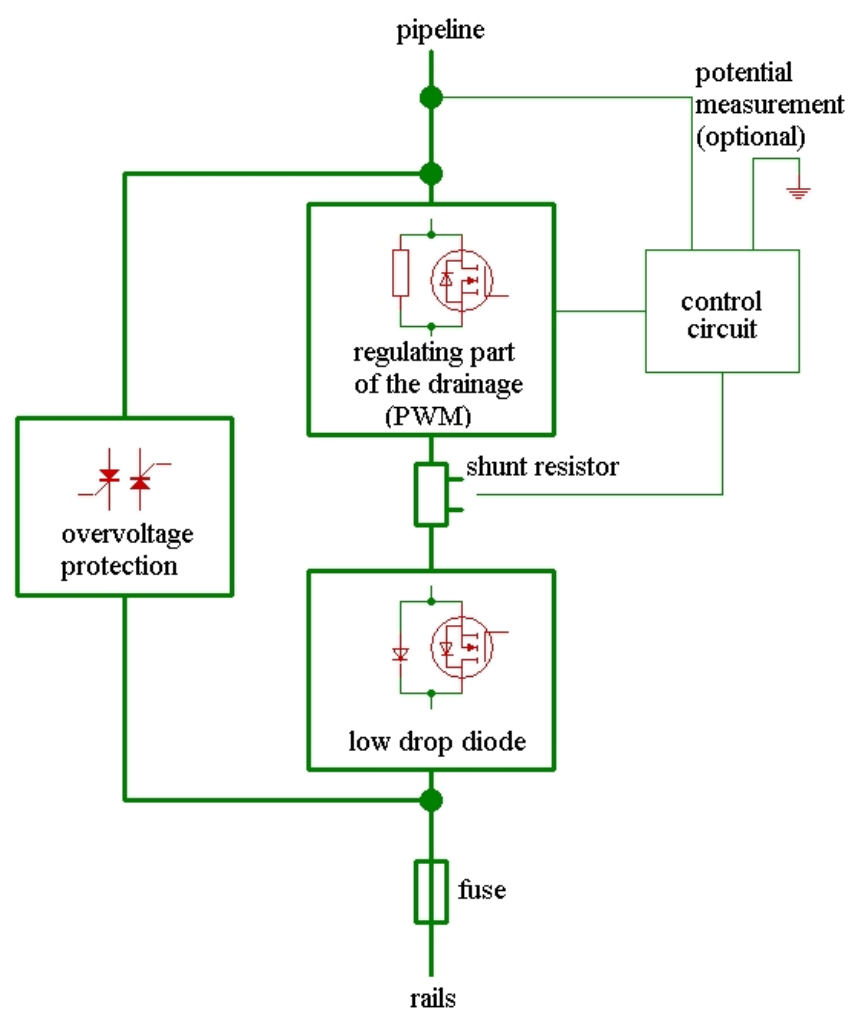

Fig. 2. Block diagram of the regulated electrical drainage, developed by our team.

The apparatus that was used for performing measurements on the tramway track consists of laptops and measuring devices based on USB6210 converters by National Instruments. Their inputs are connected via simple resistive dividers, or directly via small protective resistors. Overvoltage protection is solved with the use of transils and the inputs are equipped with a simple RC low-pass first order filter, set to $4 \mathrm{kHz}$. A clamp ammeter PROVA2000, which has a conversion ratio of $2000 \mathrm{~A}$ to $2 \mathrm{~V}$ was used for current measurement. Software for measurement and data analyse was created in LabVIEW 8.6. Later, almost the same apparatus was used to perform laboratory measurements. The only difference was that LEM LA55P was used as a current sensor.

When the drainage was tested on a tram track, it was found out that in some moments, cyclic switching between two neighbouring control stages occurred for a few seconds. It does not occur very often, just a few times a day, but it is still unacceptable, with regard to track circuit interference.

Figure 3 shows such cyclic switching between two control stages. In this case it was control stage 0 (permanently switched on, with no PWM) and control stage 1 (PWM duty cycle $15: 16,9.375 \mathrm{~ms}$ switched on a $0.625 \mathrm{~ms}$ switched off) one PWM period takes $10 \mathrm{~ms}$.

According to Standard ČSN 342613, current harmonics must not exceed the values presented in Table I.

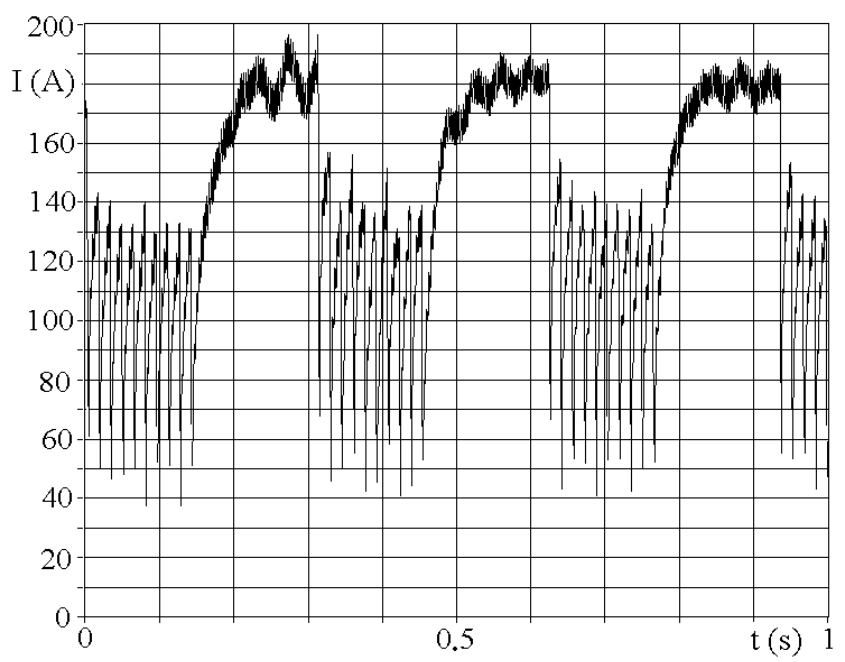

Fig. 3. Measurement on a tram track, cyclic changing of control stages.

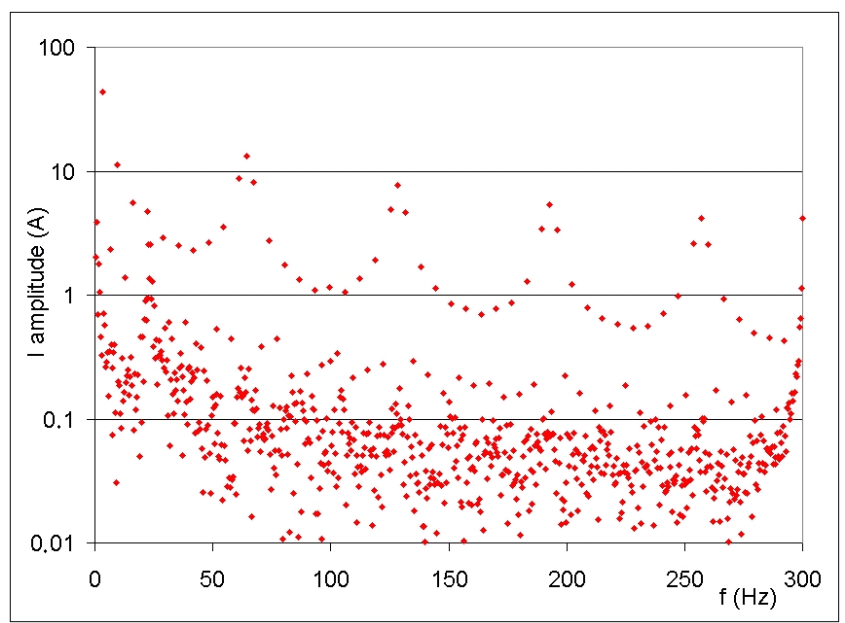

Fig. 4. Harmonic spectrum of the current from Fig. 3.

TABLE I. PROTECTIVE FREQUENCY BANDS AND CURRENT LIMITS ACCORDING TO STANDARD ČSN 342613 AND HARMONIC VALUES MEASURED ON A TRAM TRACK (FIG. 3 AND FIG. 4).

\begin{tabular}{|c|c|c|c|}
\hline \multirow{3}{*}{$\begin{array}{l}\text { Protective } \\
\text { freq. band } \\
\text { (Hz) }\end{array}$} & \multicolumn{2}{|c|}{ Limits stated by Standard ČSN 342613} & \multirow{3}{*}{$\begin{array}{l}\text { Aggregate } \\
\text { RMS values } \\
\text { from Fig. } 4\end{array}$} \\
\hline & \multicolumn{2}{|c|}{ Duration } & \\
\hline & permanent & $<0.52 \mathrm{~s}$ & \\
\hline $44-54$ & $0.26 \mathrm{~A}$ & $0.50 \mathrm{~A}$ & 1,98 \\
\hline $68-80$ & $0.11 \mathrm{~A}$ & $0.50 \mathrm{~A}$ & 2,03 \\
\hline \multirow[t]{2}{*}{$262-280$} & $0.13 \mathrm{~A}$ & $0.50 \mathrm{~A}$ & 0,91 \\
\hline & \multicolumn{2}{|c|}{$\begin{array}{c}\text { For duration }<0.12 \mathrm{~s}, \text { current values are } \\
\text { not restricted. }\end{array}$} & \\
\hline
\end{tabular}

Since each protective band contains several current harmonic components, it is necessary to calculate an aggregate RMS values to make it possible to make a comparison with the limits from Table I. Measuring software calculates the harmonic spectrum as a series of amplitudes, so obtained values must also be converted to RMS. Aggregate RMS values was calculated by using (1) [9]

$$
I_{R M S}=\frac{1}{\sqrt{2}} \sqrt{\sum_{k=1}^{n} I_{k}^{2}} .
$$

There is no point in comparing measurement results from Table I with limits stated by the Standard, because this measurement was done on a tram track, so the Standard does 
not apply to these values. In addition, the drainage was connected without a coupling inductor, which is used in railway drainage types. Nevertheless, it is obvious that these values much exceed the limits stated by the Standard, which means that it is necessary to deal with this problem before the device is tested on a railway track.

Coupling inductors that are used on railways usually have a value of 10 to $40 \mathrm{mH}$, and their rated current is usually $100 \mathrm{~A}$. For this reason, maximum current value that can be set on the drainage is $100 \mathrm{~A}$. Inductor inductance will lower harmonic values. This was first tested by simulation in the Microcap program [10]. It was found out that if inductance is $40 \mathrm{mH}$ and current $100 \mathrm{~A}$, harmonic values will correspond to the Standard, but if inductance is $10 \mathrm{mH}$ and current $100 \mathrm{~A}$, harmonic values in the $68 \mathrm{~Hz}-80 \mathrm{~Hz}$ band will be exceeded.

\section{SOlving The Problem WITH CURRENT HaRMONIC COMPONENTS WHICH EXCEED THE LIMITS}

As most simple solution of the problem, a passive filter consisting of a coupling inductor and a resistor with a condenser was chosen (Fig. 5). Despite that it has some unfavourable features when utilizing in distribution systems [11], for this application it is suitable.

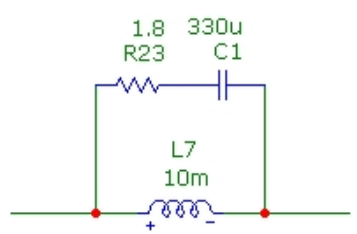

Fig. 5. Passive filter for current harmonics mitigation.

According to simulation results presented in [10], this filter will sufficiently reduce harmonic component values within the $68 \mathrm{~Hz}-80 \mathrm{~Hz}$ band, and partly also in the $44 \mathrm{~Hz}-$ $54 \mathrm{~Hz}$ band, but at the same time, it will increase these values in the $262 \mathrm{~Hz}-280 \mathrm{~Hz}$ band. For this reason, it can only be used in places where the track circuit frequency is $75 \mathrm{~Hz}$.

To further verify the functionality of this solution, it was necessary to do practical measurements. Since the problem has still not been solved in a reliable way, it was impossible to measure on a railway track equipped with track circuits under normal operation conditions. As we are also do not know any place on the railway where there is drainage but no track circuits, the decision was made to create a laboratory model and do measurements on this model. For laboratory conditions, it was decided that current and voltage values would not be identical with real life conditions, but that they would be sized down on a certain scale (Table II). The fundamental parts of the control circuit of the drainage, including the algorithm in the control microcontroller, remained the same in the model as in the actual drainage.

Current in the circuit was measured with the use of a LEM current sensor, recorded by a computer with a USB6210 converter and software created in the Lab VIEW system. Harmonic current analysis was also done using LabVIEW created software.
TABLE II. CURRENT, VOLTAGE AND IMPEDANCE SCALES FOR THE LABORATORY MODEL OF THE DRAINAGE.

\begin{tabular}{|c|c|c|c|}
\hline Current scale & $1: 1000$ & $1 \mathrm{~A}$ & $1 \mathrm{~mA}$ \\
\hline Voltage scale & $1: 10$ & $10 \mathrm{~V}$ & $1 \mathrm{~V}$ \\
\hline & & $1 \Omega$ & $100 \Omega$ \\
Impedance scale & $100: 1$ & $1 \mathrm{mH}$ & $100 \mathrm{mH}$ \\
& & $100 \mu \mathrm{F}$ & $1 \mu \mathrm{F}$ \\
\hline
\end{tabular}

The diagram showing the connection of the laboratory model of the drainage is presented in Fig. 6.

Inductance and resistance values of the rails were estimated based on standards, literature and experiences from previous measurements [10], [12], [13].

In computer simulation, condenser capacity was designed to be $400 \mu \mathrm{F}$. After the first experiments with the model, it was found out that this capacity value ( $4 \mu \mathrm{F}$ for the model) was not ideal. A lower capacity of $3.3 \mu \mathrm{F}$ led to better results, and so this value was used in the model.

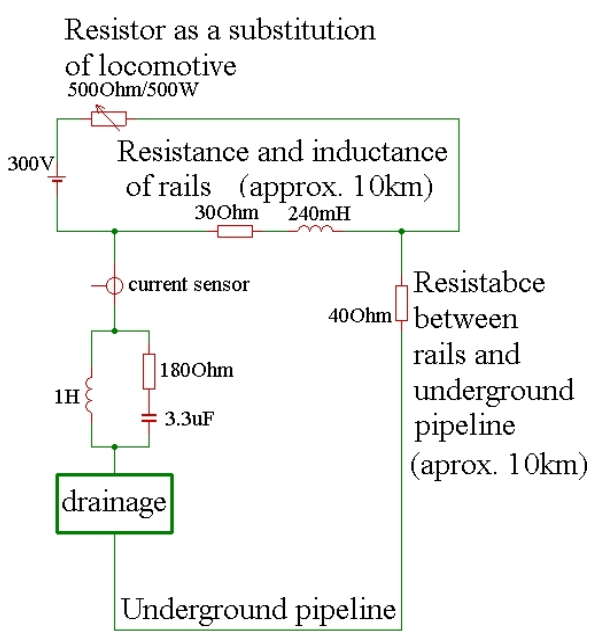

Fig. 6. Laboratory model of the drainage, the filter and a traction circuit.

The following experiment was done on the model. Conditions were changed using the $500 \Omega$ resistor that represents a locomotive, so that the drainage switched cyclically between two neighbouring control stages. All possible situations which may occur during operation were tested one by one, i.e. $0-1,1-2$ etc., up to 15-16.

The value of current flowing through the drainage was set to $100 \mathrm{~mA}$ (corresponding to $100 \mathrm{~A}$ in reality). This current really flowed through the drainage during the experiment, with a measurement deviation of $\pm 3 \mathrm{~mA}$. This is the highest acceptable current value, and therefore also the most unfavourable case, because the maximum allowed current value for coupling inductors used for railway drainage is $100 \mathrm{~A}$.

As a result of aging, condenser parameters may change during the service life of the filter. For this reason, measurements were done not only for condenser capacity $3.3 \mu \mathrm{F}$, but also $2.2 \mu \mathrm{F}$ and $4.7 \mu \mathrm{F}$. Figure 7 and Fig. 8 show current waveform when control stage is changing between 1 and 2. Figure 7 is without filter (only inductor $10 \mathrm{mH}$ ); Fig. 8 is with filter when capacity is $3.3 \mu \mathrm{F}$.

Current harmonics are shown in Table III and they are also presented in graphic form in Fig. 9.

From Table III and Fig. 9 it is clear that in the $68 \mathrm{~Hz}-$ $80 \mathrm{~Hz}$ frequency band, current harmonic values exceed the 
limits if the filter is not used, while with the filter they are within limits. The filter also works well in cases where condenser pacity changes from $3.3 \mu \mathrm{F}$ to $2.2 \mu \mathrm{F}$ or $4.7 \mu \mathrm{F}$, e.g. as a result of aging.

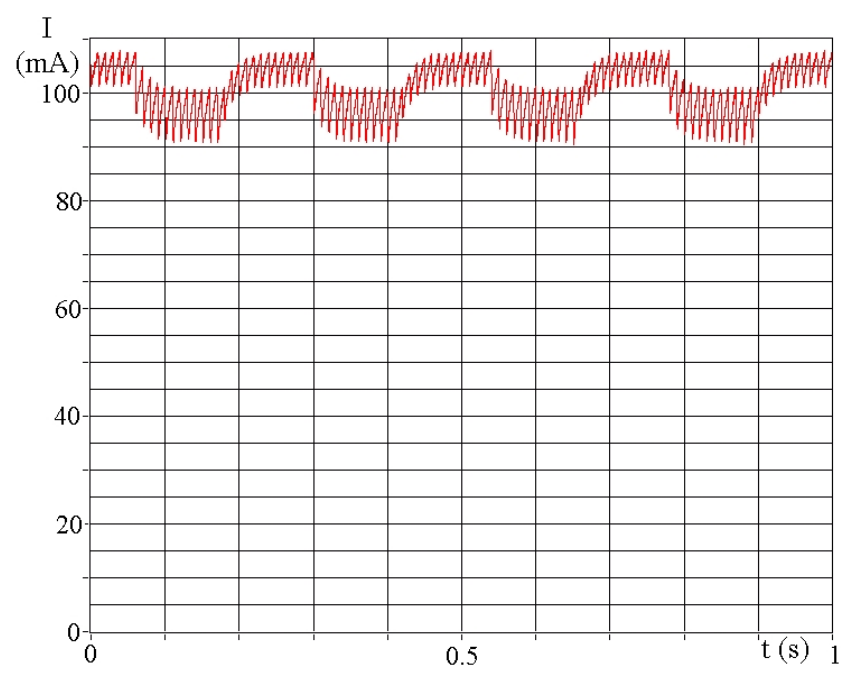

Fig. 7. Current waveform, control stage changing 1-2 without filter (only inductor $10 \mathrm{mH}$ ).

The filter can also lower harmonic values for the $44 \mathrm{~Hz}-54 \mathrm{~Hz}$ frequency band, but in this case it is not necessary to use it because harmonic values comply with the Standard anyway.

For the $262 \mathrm{~Hz}-280 \mathrm{~Hz}$ frequency band, however, this filter increases harmonic values above the allowed level. Without the filter, the values are within limits stated by the Standard, so it is unnecessary and not advisable to use the filter.

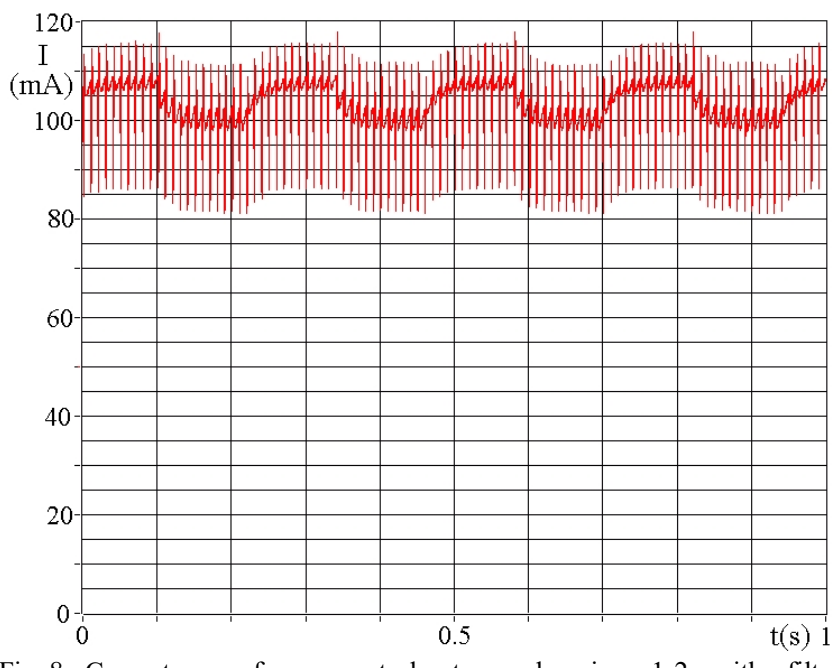

Fig. 8. Current waveform, control stage changing $1-2$ with filter (capacity $3.3 \mu \mathrm{F}$ ).

TABLE III. LABORATORY MEASUREMENT RESULTS - CURRENT HARMONICS IN PROTECTIVE FREQUENCY BANDS. CURRENT VALUES ARE IN MA, AND THEY HAVE BEEN CALCULATED FROM MODEL VALUES TO ACTUAL VALUES.

\begin{tabular}{|c|c|c|c|c|c|c|c|c|c|c|c|c|}
\hline \multirow{3}{*}{$\begin{array}{c}\text { Control } \\
\text { stage }\end{array}$} & \multicolumn{3}{|c|}{ Without filter } & \multicolumn{3}{|c|}{ With filter, $C=3.3$ uf } & \multicolumn{3}{|c|}{ With filter, $\mathrm{C}=\mathbf{2 . 2}$ uf } & \multicolumn{3}{|c|}{ With filter, $C=4.7$ uf } \\
\hline & \multicolumn{3}{|c|}{ Frequency band (Hz) } & \multicolumn{3}{|c|}{ Frequency band (Hz) } & \multicolumn{3}{|c|}{ Frequency band $(\mathrm{Hz})$} & \multicolumn{3}{|c|}{ Frequency band (Hz) } \\
\hline & $44-54$ & $68-80$ & $262-280$ & $44-54$ & $68-80$ & $262-280$ & $44-54$ & $68-80$ & $262-280$ & $44-54$ & $68-80$ & $262-280$ \\
\hline 1 & 12.3 & 17.8 & 13.0 & 9.7 & 11.1 & 23.2 & 11.0 & 16.3 & 24.3 & 10.6 & 11.4 & 28.8 \\
\hline 15 & 11.0 & 9.4 & 14.2 & 11.1 & 21.0 & 26.1 & 12.1 & 13.7 & 21.8 & 10.8 & 12.5 & 18.3 \\
\hline $0-1 *$ & 154.0 & 147.3 & 45.9 & 97.9 & 58.5 & 162.6 & 109.2 & 71.1 & 137.1 & 84.3 & 70.9 & 183.9 \\
\hline $1-2$ & 149.5 & 146.6 & 43.5 & 99.8 & 60.6 & 179.0 & 119.0 & 83.2 & 154.6 & 81.3 & 67.1 & 194.2 \\
\hline $2-3$ & 147.7 & 140.3 & 41.4 & 99.9 & 62.7 & 176.3 & 121.6 & 88.3 & 164.3 & 94.7 & 86.7 & 224.6 \\
\hline $3-4$ & 154.6 & 156.5 & 43.4 & 103.5 & 71.7 & 201.6 & 120.8 & 87.6 & 162.9 & 88.3 & 70.4 & 211.4 \\
\hline $4-5$ & 149.2 & 139.4 & 42.6 & 108.4 & 69.8 & 186.5 & 140.2 & 96.1 & 176.5 & 98.4 & 86.2 & 231.8 \\
\hline $5-6$ & 153.0 & 144.3 & 44.0 & 101.7 & 72.2 & 183.3 & 122.4 & 85.3 & 150.3 & 88.0 & 75.6 & 204.4 \\
\hline 6-7 & 142.3 & 148.8 & 42.9 & 102.2 & 72.1 & 178.6 & 118.2 & 89.3 & 150.0 & 95.7 & 73.6 & 213.2 \\
\hline $7-8$ & 140.8 & 157.7 & 49.9 & 113.6 & 73.7 & 210.9 & 121.0 & 89.0 & 152.1 & 91.4 & 82.6 & 214.2 \\
\hline $8-9$ & 141.0 & 151.9 & 47.5 & 103.6 & 72.1 & 181.9 & 121.8 & 93.7 & 155.4 & 91.1 & 84.4 & 213.1 \\
\hline $9-10$ & 143.9 & 152.3 & 57.1 & 103.1 & 74.8 & 190.2 & 117.5 & 90.6 & 145.1 & 102.1 & 103.7 & 226.6 \\
\hline $10-11$ & 148.2 & 142.9 & 45.7 & 108.5 & 88.2 & 188.4 & 121.3 & 89.1 & 143.5 & 90.8 & 80.7 & 205.0 \\
\hline $11-12$ & 152.8 & 156.0 & 44.7 & 106.6 & 69.7 & 175.6 & 116.6 & 84.9 & 145.5 & 90.2 & 85.7 & 204.1 \\
\hline $12-13$ & 141.0 & 146.1 & 46.9 & 106.9 & 69.6 & 182.5 & 123.1 & 87.9 & 162.6 & 92.2 & 81.4 & 201.4 \\
\hline $13-14$ & 144.9 & 142.4 & 51.6 & 119.5 & 86.3 & 198.5 & 119.2 & 88.2 & 156.4 & 102.5 & 76.5 & 223.1 \\
\hline $14-15$ & 141.2 & 147.4 & 52.1 & 118.9 & 74.2 & 198.4 & 117.7 & 107.7 & 158.8 & 105.1 & 79.3 & 214.4 \\
\hline $15-16^{*}$ & 151.2 & 149.9 & 48.6 & 113.7 & 63.9 & 183.2 & 111.6 & 97.2 & 151.1 & 98.4 & 81.4 & 206.7 \\
\hline \multicolumn{13}{|c|}{ limits stated by CSN342613 } \\
\hline & 260 & 110 & 130 & 260 & 110 & 130 & 260 & 110 & 130 & 260 & 110 & 130 \\
\hline
\end{tabular}

*Note: control stage 0 means a permanent switch ON (the lowest resistance of the drainage); control stage 16 means a permanent switch OFF (the highest resistance of the drainage) 


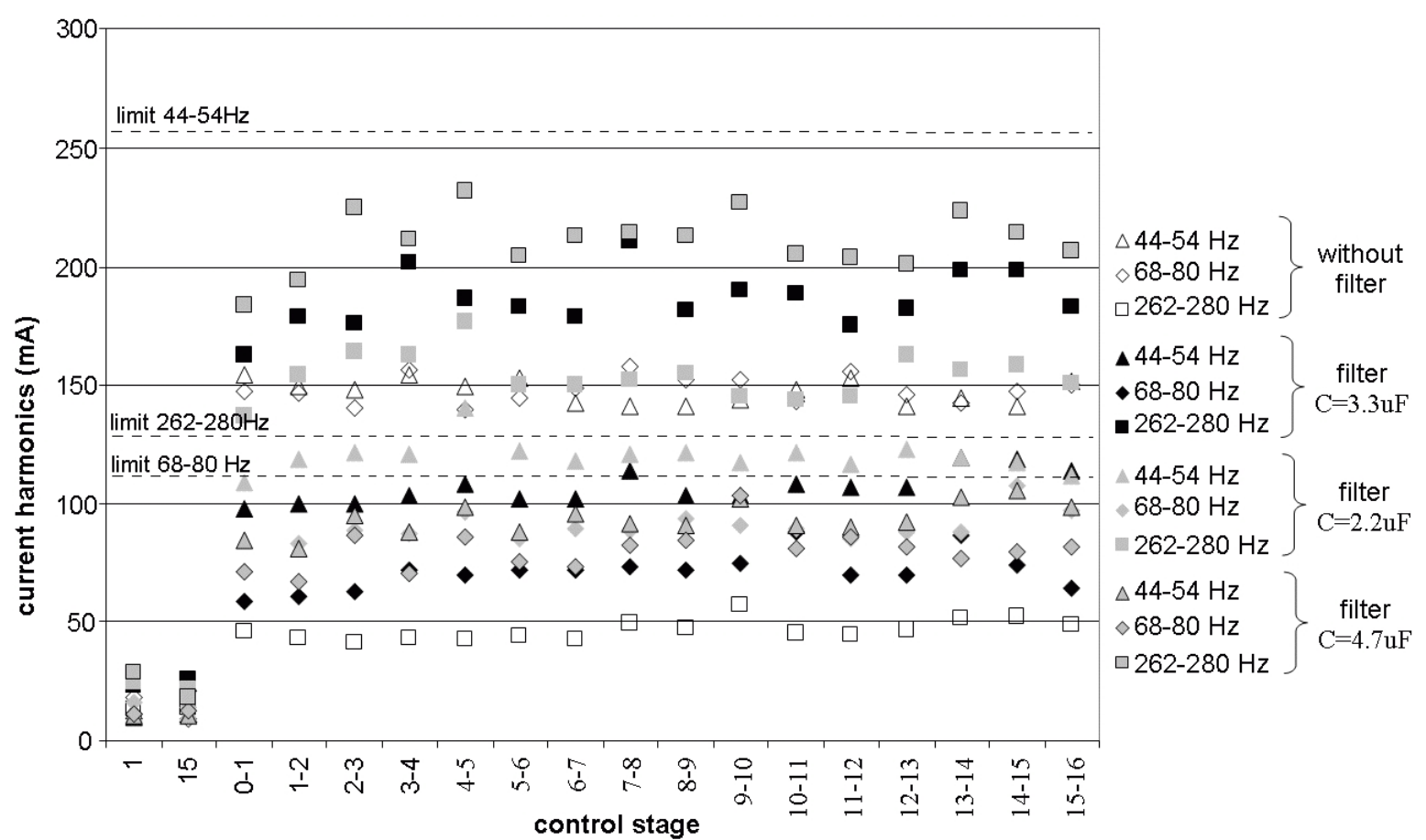

Fig. 9. Measurement results - current harmonics in protective frequency bands. Currents are in $\mathrm{mA}$, recalculated from model values to actual values.

\section{DISCUSSION}

The newly developed prototype of regulated electrical drainage is currently (March 2018) undergoing long-term testing on a tramway track in Ostrava city. This testing has been going on for ten months, and the prototype is working perfectly. If the prototype works like this for two years, the investor may replace the remaining non-regulated drainage systems in Ostrava with these newly developed regulated drainage systems. This would mean an investment of some 15,000 EUR. (Currently, about a quarter of all of the approximately 30 tram drainages in Ostrava are nonregulated.) If this implementation is successful, this type of drainage may be used in other cities as well.

Using this drainage on railways would have even more economic potential. Drainage systems which are designed for railways are at least three times more expensive than tram drainage systems. For this reason, the investor's next requirement is to prepare this regulated electrical drainage, so that it can be used on railways.

In the case of the railway, however, it is absolutely necessary to solve the electromagnetic compatibility of the drainage with track circuits. Even for testing, drainage must be approved based on Regulation 34 issued by Railway Infrastructure Administration, state organisation, before it is installed on the railway. The device must be approved by the Railway Research Institute, j.s.c., or another institution that meets the conditions stated by Standard CSN EN 50129.

The approval process is complex and lengthy. Before the investor starts this process, it is necessary that the drainage prototype fulfils all of the known requirements for railway operation, the most important one being its compliance with protective frequency limits stated by ČSN 342613. To ensure a good result of the approval process, it is also necessary that the designer and the manufacturer of the drainage is familiar with the mechanism that leads to the occurrence of interferences between the drainage and track circuits, so that adequate solutions may be selected to eliminate these influences.

Both computer simulation and laboratory tests play an important role in designing these solutions. The passive filter described in this paper is one of the ways which are being considered. At the same time, we are also working on other solutions, which are not discussed here, e.g. adjusting the regulation algorithm of the drainage or using active filter [14].

\section{CONCLUSIONS}

The authors of this paper have developed a prototype of regulated electrical drainage for tram traction with current regulation with the use of PWM. To be able to use the drainage on railway tracks as well, the authors have also investigated the compatibility of the prototype with track circuits. After initial tests on a tram track (where there are no track circuits), it was seen that in the case of the $68 \mathrm{~Hz}$ $80 \mathrm{~Hz}$ protective frequency band, the limits of harmonics stated by the Standard might be exceeded.

To solve this problem, a RLC passive filter was designed. The problem was solved first by computer simulation [10] and then by measurement on a laboratory model, which is described in this paper.

It was found out that the designed filter is a good solution when track circuit frequency is $75 \mathrm{~Hz}$. For other frequencies, it is not necessary to use the filter, or its use even worsens the situation. Values of filter components must be designed based on the inductance of a specific drainage coupling inductor installed on the location where the drainage is supposed to operate.

Until now, the only component that was used to eliminate unwanted frequencies in electrical drainage was an inductor.

\section{REFERENCES}

[1] M. Bartlomiejczyk, S. Mirchevski, "Reducing of energy consumption in public transport - results of experimental exploitation of super capacitor energy bank in Gdynia trolleybus system", in Proc. 16th 
Int. Power Electronics and Motion Control Conf. and Exposition (PEMC 2014), Antalya, Turkey 2014, pp. 94-101. DOI: 10.1109/EPEPEMC.2014.6980616.

[2] A. W. Peabody, Control of pipeline corrosion. NACE International The Corrosion Society, Houston, Texas, USA, 2001.

[3] A. Ogunzola, A. Mariscotti, Electromagnetic compatibility in railways Analysis and management. Springer, New York, USA 2013. DOI: 10.1007/978-3-642-30281-7.

[4] A. Dolara, M. Gualdoni, S. Leva, H. Shadmehr, R. Zich, "Reduced models for the EMC analysis of high speed railway systems", in Proc. Asia-Pacific Symposium on Electromagnetic Compatibility (APEMC 2012), Singapore, 2012, pp. 925-928. DOI: 10.1109/APEMC.2012.6237874.

[5] CSN 342613 ed.3. Railway Signalling Equipment - Track circuits and outer condition for their function. Praha: UNMZ, 2014, sorting signature: 342613 .

[6] V. Kolar, R. Hrbac, T. Mlcak, J. Dudek, "Selecting a suitable controlling algorithm for a regulated electric drainage", in Proc. 18th Int. Scientific Conf. Electric Power Engineering (EPE 2017), Dlouhe Strane, 2017. DOI: 10.1109/EPE.2017.7967332.

[7] M. Repka, R. Danel, Z. Neustupa, "Intelligent control of treatment technological processes in preparation plants using neural networks", in Conf. Proc. (SGEM 2013), Albena, 2013, pp. 441-447.

[8] P. Horowitz, W. Hill, The Art of Electronics. Cambridge university press 1989.

[9] J. Bird, Higher engineering mathematics. Elsevier, Oxsford, 2006.

[10] V. Kolar, R. Hrbac, T. Mlcak, "Mitigation of interferences between electrical regulated drainage and track circuits", in Proc. 9th Int. Scientific Symposium on Electrical Power Engineering (Elektroenergetika 2017), Stara Lesna, 2017, pp. 142-145.

[11] H. Rui, W. Jian, L. Yuchao, "Generalized design of shunt active power filter with output LCL filter", Elektronika ir Elektrotechnika, vol. 20, no. 5, pp. 65-71, 2014. DOI: 10.5755/j01.eee.20.5.3910.

[12] L. Ivanek, V. Mostyn, K. Schee, J. Grun, "The sensitivity of the input impedance parameters of track circuits to changes in the parameters of the track", Advances in Electrical and Electronic Engineering, vol. 15, no. 1, pp. 77-83, 2017. DOI: 10.15598/aeee.v15i1.1996.

[13] CSN EN 50122-2. Railway applications - Fixed installations Electrical safety, earthing and the return circuit - Part 2: Provisions against the effects of stray currents caused by d.c. traction systems. Praha: UNMZ, 2011, sorting signature: 341520.

[14] V. Kolar, R. Hrbac, T. Mlcak, "Regulated electric drainage and its interference with track circuits", Advances in Electrical and Electronic Engineering, submitted for publication. 